\title{
Synthetic memory circuits for tracking human cell fate
}

\author{
Devin R. Burrill, ${ }^{1,3}$ Mara C. Inniss, ${ }^{1,3}$ Patrick M. Boyle, ${ }^{1}$ and Pamela A. Silver ${ }^{1,2,4}$ \\ ${ }^{1}$ Department of Systems Biology, Harvard Medical School, Boston, Massachusetts 02115, USA; ${ }^{2}$ The Wyss Institute \\ of Biologically Inspired Engineering, Boston, Massachusetts 02115, USA
}

\begin{abstract}
A variety of biological phenomena, from disease progression to stem cell differentiation, are typified by a prolonged cellular response to a transient environmental cue. While biologically relevant, heterogeneity in these long-term responses is difficult to assess at the population level, necessitating the development of biological tools to track cell fate within subpopulations. Here we present a novel synthetic biology approach for identifying and tracking mammalian cell subpopulations. We constructed three genomically integrated circuits that use bistable autoregulatory transcriptional feedback to retain memory of exposure to brief stimuli. These "memory devices" are used to isolate and track the progeny of cells that responded differentially to doxycycline, hypoxia, or DNAdamaging agents. Following hypoxic or ultraviolet radiation exposure, strongly responding cells activate the memory device and exhibit changes in gene expression, growth rates, and viability for multiple generations after the initial stimulus. Taken together, these results indicate that a heritable memory of hypoxia and DNA damage exists in subpopulations that differ in long-term cell behavior.
\end{abstract}

[Keywords: synthetic circuit; memory; bistability; human cell fate; DNA damage; hypoxia]

Supplemental material is available for this article.

Received February 6, 2012; revised version accepted May 22, 2012.

Biological heterogeneity exists in most cell populations; even isogenic populations exhibit some natural cell-tocell variability in parameters including gene expression and cell morphology (Bishop et al. 2006). Heterogeneity can result from factors such as noise in gene expression and signal transduction, epigenetic modifications, and cell age (Avery 2006; Bishop et al. 2006). A consequence of this diversity is that not all cells in a population will respond identically to a given stimulus. Biological systems can take advantage of such heterogeneity to produce specific cell types (e.g., differentiation) or optimize fitness in fluctuating environments (e.g., immunity) (Acar et al. 2008). Conversely, heterogeneity can leave some cell subpopulations more sensitive to drug treatment (e.g., chemotherapy) or disease states (e.g., metastasis) (Murray-Zmijewski et al. 2008). Distinct cell fates can be heritably encoded using multiple gene regulatory strategies, including epigenetic marks, stable cytoplasmic factors, and transcriptional autoregulatory circuits (Burrill and Silver 2011). Thus, biological diversity can produce cell subpopulations harboring different memories of an experienced stimulus.

By the very nature of its heterogeneity, memory of a biological decision is difficult to study. Population-level

\footnotetext{
${ }^{3}$ These authors contributed equally to this work.

${ }^{4}$ Corresponding author

E-mail pamela_silver@hms.harvard.edu

Article is online at http://www.genesdev.org/cgi/doi/10.1101/gad.189035.112.
}

data can obscure subpopulations (Bishop et al. 2006), and single-cell experiments remain expensive, technically difficult, and hard to scale (Spiller et al. 2010). Studies of biological memory require a technique for tracking a cellular decision through cell division. Recombinase systems are commonly used to confer a permanent genomic mark in lineage-tracing studies; however, DNA rearrangement and recombinase expression can have off-target effects that negatively affect genomic fidelity (Forni et al. 2006). Furthermore, tunable, rewriteable DNA recombinase-based memory has only recently been demonstrated in bacteria (Bonnet et al. 2012) and has yet to be developed in eukaryotic cells.

One solution is the application of synthetic, transcriptional autoregulatory circuits to track heritable, differential responses to a stimulus. In this circuit design, a stimulus induces transcription of a trigger gene expressing a transactivator, which binds the promoter of a second gene. The second gene produces more of the same transactivator, initiating a positive feedback loop, or memory (Fig. 1A). Memory is self-sustainable when the input exceeds the circuit's bistable threshold for feedback, allowing the circuit to switch to an alternative state that is transmitted through cell division. Examples of this in nature include the cell cycle and cell differentiation (Burrill and Silver 2010), and synthetic versions have been built in bacteria, yeast, and mammalian cells (for review, see Haynes and Silver 2009; Burrill and Silver 2010). In recent work, we 


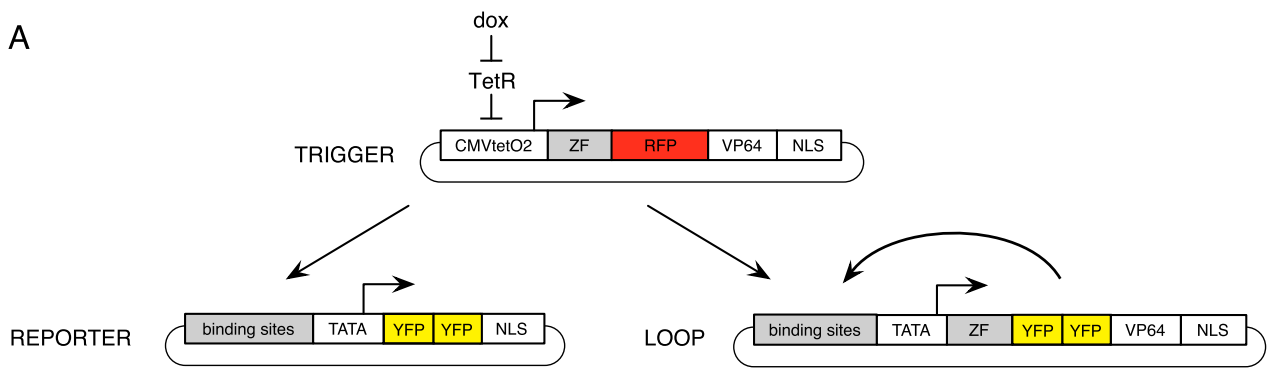

B

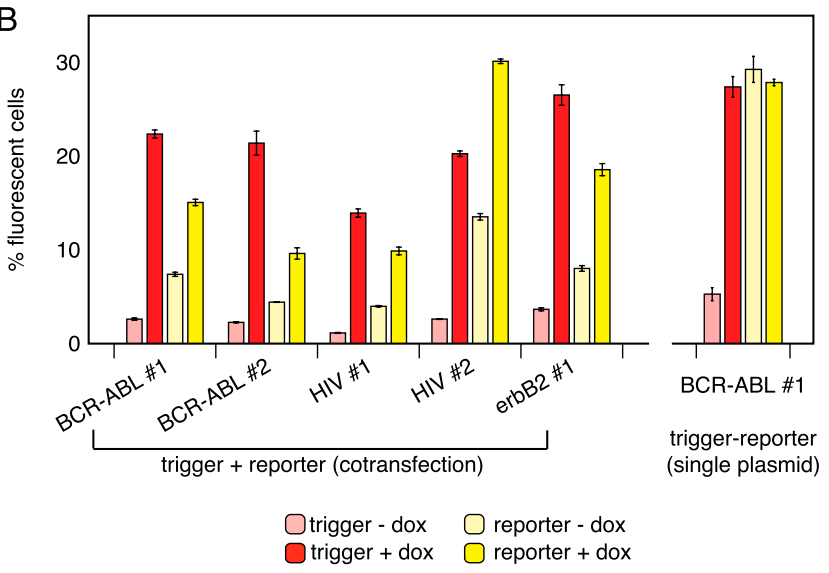

C

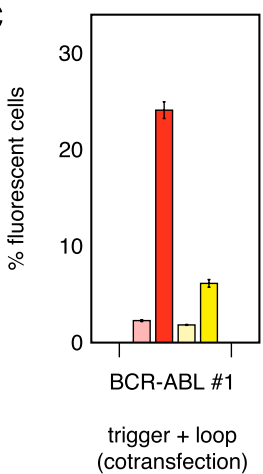

Otrigger - dox $\bigcirc$ loop - dox $\bigcirc$ trigger + dox $\bigcirc$ loop + dox
D

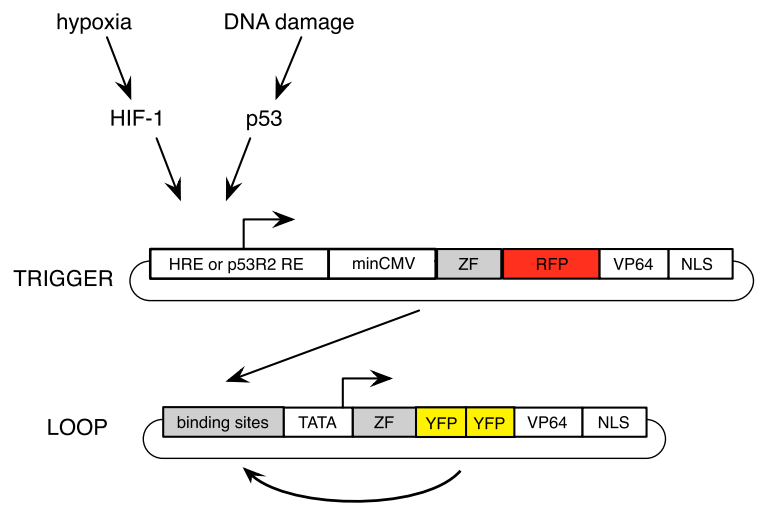

$\mathrm{E}$

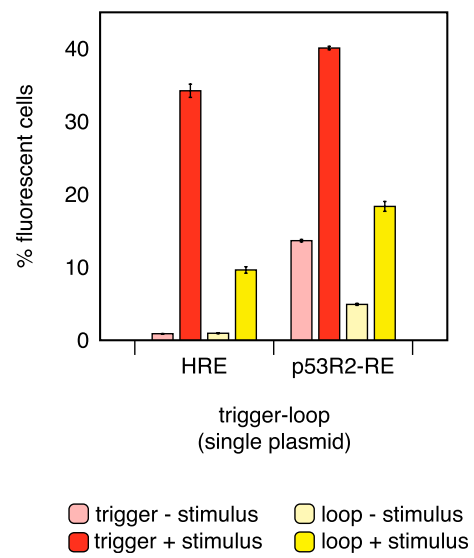

Figure 1. Design and testing of trigger and loop genes. $(A)$ Schematic of dox trigger, reporter, and loop genes. $(B)$ Synthetic ZFs $(B C R-$ $\mathrm{ABL} \# 1$ and 2, HIV \#1 and 2, and erbB2 \#1) were tested as transactivators via cotransfection with corresponding reporters. BCR-ABL \#1 was also tested on a single plasmid with its corresponding reporter gene. $(C)$ The BCR-ABL \#1 trigger and loop were tested via cotransfection on separate plasmids. $(D)$ The BCR-ABL \#1 trigger was adapted to be sensitive to hypoxia or DNA damage. (E) The HRE and p53R2-RE triggers were tested on a single plasmid with their corresponding loop genes. $(B, C, E)$ FACS determined the percent of cells positive for trigger RFP and reporter or loop YFP. Values represent mean $\pm \mathrm{SE} ; n=3$.

constructed a memory circuit in yeast that detects DNA repair, allowing for isolation of cells that initiated a repair response above the circuit's bistable threshold (Burrill and Silver 2011). Strongly responsive cells exhibited a heritable damage response that was distinct from less-responsive cells for many generations.

Here we report the construction and implementation of synthetic memory circuits in human cells to track differential cellular decisions following a global stimulus. Activation of the device was linked to endogenous hypoxia and DNA damage response pathways, as these stressors elicit heterogeneous responses at the single-cell level (Bristow and Hill 2008; Murray-Zmijewski et al. 2008). A synthetic memory device that responds to low oxygen $\left(\mathrm{O}_{2}\right)$ concentrations could help study the sustained effects of hypoxic exposure during tumor formation. 
Hypoxia stabilizes the HIF-1 transcription factor, which can activate or silence target genes as well as increase genomic instability by mediating the bypass of DNA repair checkpoints (Chen et al. 2006; Bristow and Hill 2008; Denko 2008; Lee et al. 2009; Lu et al. 2011). Tumors can harbor cell subpopulations that have been exposed to acute or chronic hypoxia and subsequently reoxygenated, and these tumors are associated with a more aggressive disease (Bristow and Hill 2008). A memory device activated by HIF-1 could potentially detect, isolate, and track these subpopulations within the heterogeneous tumor microenvironment to determine their specific contributions toward tumor development and metastasis.

Like hypoxia, DNA damage also produces a complex array of biological responses at the single-cell level. Linking a memory circuit to native DNA damage pathways could help identify how DNA damage responses are transmitted to subsequent generations and impact long-term cell behavior. The variable activation of the tumor suppressor p53 largely determines a single cell's response to DNA damage (Murray-Zmijewski et al. 2008). A memory device triggered at the level of a p53-induced repair factor, such as the ribonucleotide reductase p53R2, would facilitate the isolation and tracking of progeny whose ancestors underwent a repair response strong enough to activate the memory loop, versus those that did not (Tanaka et al. 2000). This could reveal how a cell's specific history of DNA damage translates into long-term biological consequences.

Collectively, our work illustrates a synthetic biology approach for studying cell heterogeneity and fate. The described genomically integrated devices enable the investigation of biological questions that require inheritance of a genetic circuit through cell division. The modularity of our system is demonstrated by the construction of memory circuits that respond to diverse and relevant stimuli. Our studies reveal the existence of a heritable biological memory of DNA damage and hypoxia, providing unique insight into protracted responses to transient stimuli.

\section{Results}

\section{Characterizing memory circuit components} via transient transfection

To engineer a memory device, we first designed a set of fluorescently labeled synthetic transcriptional activators (triggers) and their corresponding reporter genes (Fig. 1A). Each trigger gene consisted of a synthetic zinc finger $(\mathrm{ZF})$ DNA-binding domain (Hurt et al. 2003), one copy of the red fluorescent protein (RFP) mCherry (Shaner et al. 2004), the VP64 activation domain (Beerli et al. 1998), and a nuclear localization sequence (NLS) (Kalderon et al. 1984), all under the control of a doxycycline (dox)-inducible CMV-TetOx2 promoter with a human kozak sequence. ZFs were mammalian codon-optimized versions of those previously engineered by Hurt et al. (2003) to bind specifically to target DNA sequences in a BCR-ABL translocation (BCR-ABL \#1 and \#2), the erbB2 gene (erbB2 \#1), or the HIV promoter (HIV \#1 and \#2). Each reporter gene had six tandem copies of DNA-binding sites for a given ZF upstream of a minimal promoter (composed of a TATA sequence and human kozak sequence), and its proteincoding region encoded two copies of the yellow fluorescent protein (YFP) variant Venus (Shaner et al. 2005) tagged with an NLS (Fig. 1A). In the presence of dox, trigger genes were expected to express RFP and a functional transactivator that should bind to its corresponding reporter binding sites, producing a YFP signal.

To evaluate the functionality of our constructs in human cell culture, triggers and reporters were built on separate plasmids and transiently cotransfected in a human U2OS cell line that expresses the Tet repressor (Supplemental Table S1). Following the addition of dox, trigger RFP and reporter YFP coexpression was monitored by fluorescence-activated cell sorting (FACS) (Fig. 1B). All triggers activated transcription of their target reporters by at least twofold. The HIV \#2 reporter exhibited the most leaky expression, with $>10.0 \%$ of cells expressing YFP in the absence of dox. Trigger/reporter pairs were specific and orthogonal to one another, as minimal YFP expression was observed when reporters alone (Supplemental Fig. S1A) or mismatched trigger/reporter combinations (Supplemental Fig. S1B) were transfected. Thus, all triggers were capable of producing a functional transcriptional circuit.

This set of synthetic transactivators provided the components to construct autoregulatory loops intended to confer memory of a stimulus to a single cell and its progeny. In our proposed device, an input causes synthesis of an RFP-labeled transactivator, which activates expression of a 2xYFP-labeled transactivator (Fig. 1A). This protein binds to its own promoter and, given certain parameters, continues to self-activate in the absence of stimulus, resulting in sustained YFP expression. For simplicity, all memory devices were built with the BCR-ABL \#1 domain, although the above transient experiments suggested that all tested ZFs would provide similar results.

Since tracking long-term memory requires a stably integrated device, a trigger-reporter circuit was assembled on a single plasmid and tested by transient transfection for circuit activation to determine whether the circuit could be integrated in one step. On a single plasmid, the dox memory device demonstrated constitutive reporter YFP expression in the absence of dox, likely due to cis-activation caused by enhancer elements in the trigger's CMV-TetOx2 promoter (Fig. 1B; Boshart et al. 1985). However, the dox device demonstrated inducible expression of the loop gene when the trigger and loop were cotransfected on separate plasmids (Fig. 1C).

We next aimed to construct memory circuits capable of recording exposure to dox, hypoxia, or DNA damage. The hypoxia-inducible promoter we used was based on one previously engineered by Shibata et al. (2000) and is composed of five copies of HIF-1 binding sites, known as hypoxia-responsive elements (HREs), ligated to a minimal human CMV promoter. This promoter is activated when a cell triggers the HIF-1 pathway in response to hypoxia (Fig. 1D). A DNA damage-inducible promoter (p53R2-RE) was generated by linking four copies of the p53-binding site in p53R2 (Ohno et al. 2008) to a minimal human 
CMV promoter (Shibata et al. 2000). This promoter is activated when a cell executes a p53R2-mediated repair response (Fig. 1D).

Unlike the dox device, the HRE and p53R2-RE triggers do not contain strong enhancer elements and can be assembled as a single construct with the loop gene. When the hypoxia and DNA damage devices were transfected as a single plasmid and exposed to the hypoxia mimic cobalt chloride $\left(\mathrm{CoCl}_{2}\right)$ or the DNA-damaging agent neocarzinostatin (NCS), respectively, RFP and YFP were coexpressed in a significant percentage of cells above basal levels (Fig. 1E). These observations were similar whether or not the circuits were built on one plasmid (Supplemental Fig. S1C). Thus, we determined that while a dox memory cell line would require two integrations, only one was necessary to produce DNA damage and hypoxia memory cell lines. To test the capacity of the loop element to retain memory of dox, hypoxia, or DNA damage exposure, we proceeded to genomically integrate the circuits.

\section{An integrated dox memory device}

The dox trigger and loop were randomly integrated as separate genes to create the cell line MD10/TetOx2
(Supplemental Table S2). Dox exposure resulted in trigger RFP and loop YFP expression in $99.8 \%$ and $42.7 \%$ of cells, respectively, as determined by FACS (Fig. 2A) and fluorescence microscopy (Fig. 2B). Upon the removal of dox, trigger RFP turned off in most cells within $1 \mathrm{~d}$, while loop YFP achieved a bimodal distribution, such that two distinct memory and non-memory subpopulations coexisted (Supplemental Fig. S2). YFP expression persisted in a large percentage of cells for at least $3 \mathrm{~d}$ (about four generations), suggesting heritable memory loop activity (Fig. 2B). These traits were not specific to MD10/TetOx2, as multiple alternative clones were analyzed and demonstrated similar behavior (Supplemental Fig. S3).

Sustainable memory behavior in a subpopulation of dividing cells was further revealed in time-lapse fluorescence microscopy of cells recovering from dox exposure (Fig. 2C; Supplemental File S1). Distribution of YFP intensity in the memory subpopulation was constant over time, suggesting persistent protein production (Fig. 3A). Furthermore, spontaneous loop activation in the absence of dox was not observed when MD10/TetOx2 was cultured for $9 \mathrm{~d}(\sim 10$ generations), indicating that any loop activity was due solely to dox exposure (Fig. 3B). To rule out a difference in RFP and YFP protein degradation rates as causal of the observed memory behavior, cells were
A

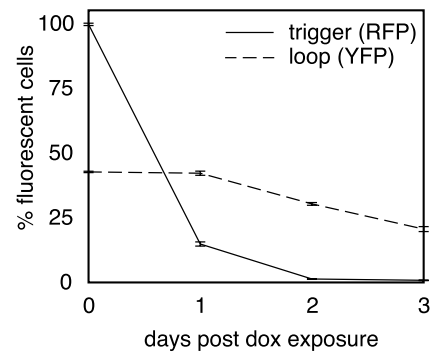

B

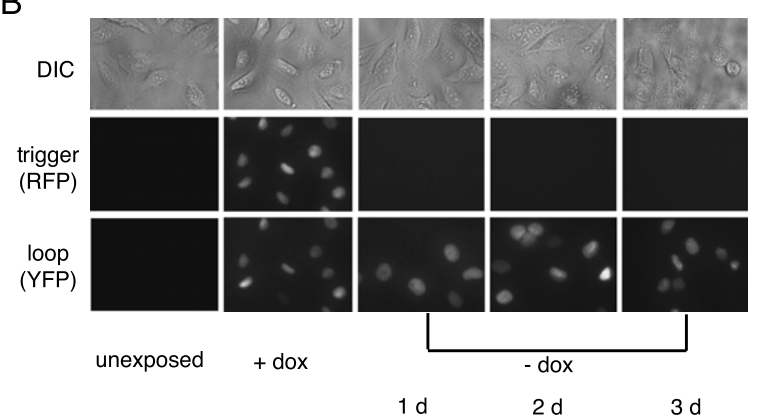

C

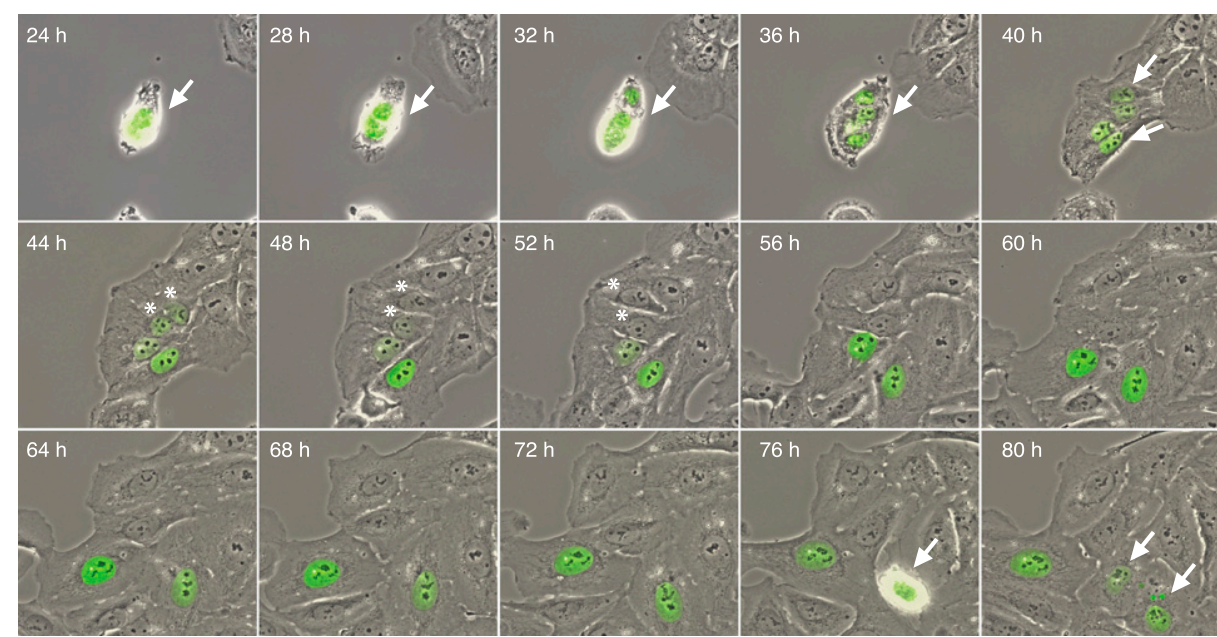

Figure 2. MD10/TetOx2 transmits memory of dox exposure. Memory behavior was analyzed by FACS $(A)$ and fluorescence microscopy $(B)$. FACS determined the percent of cells positive for trigger RFP and loop YFP. Values represent mean \pm SE; $n=3$. $(C)$ Fluorescence microscopy montage of MD10/TetOx2, 24-28 h post-dox exposure. Phase, RFP, and YFP channels were overlaid. (Arrows) Dividing memory cells; $\left({ }^{\star}\right)$ cells in which the circuit does not remain active after division. 
Burrill et al.
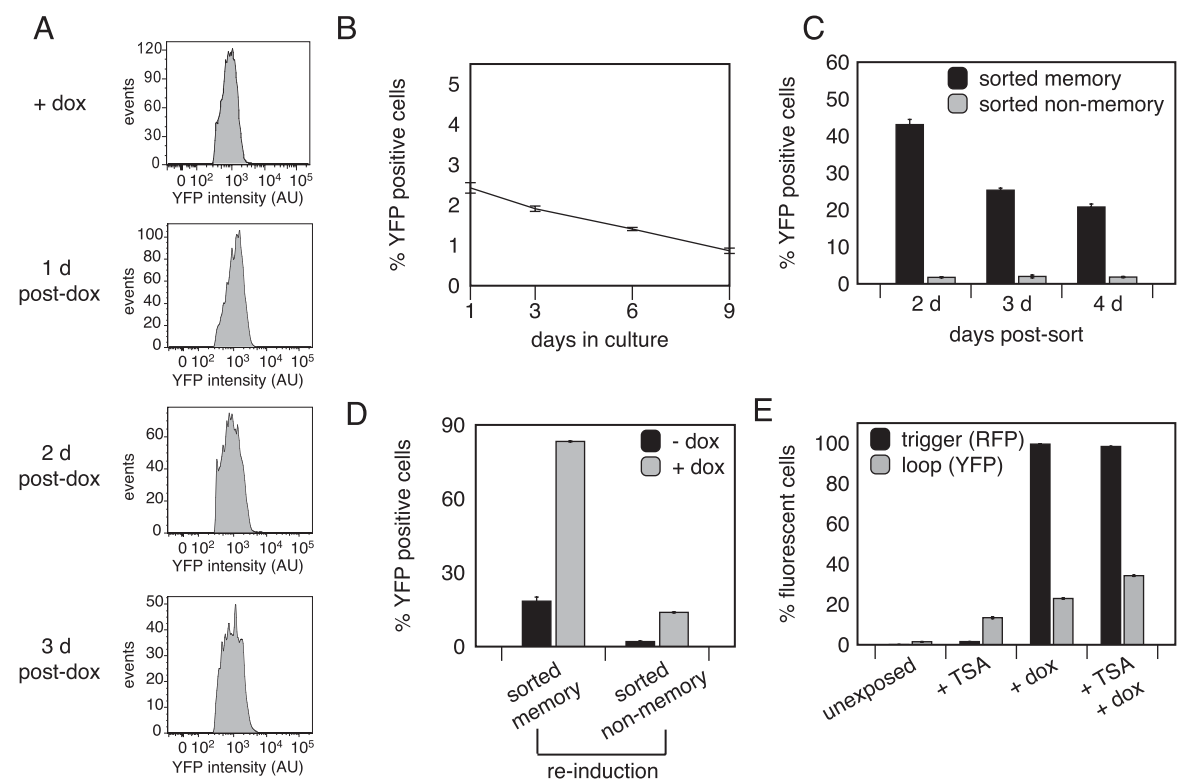

Figure 3. Further characterization of MD10/TetOx2. (A) FACS plots of the YFP intensity of the memory cell subpopulation versus the event rate at several time points post-dox exposure. $(B)$ Unexposed cells were tracked via FACS to determine the rate of spontaneous loop activation. $(C)$ Memory and non-memory cells were sorted $2 \mathrm{~d}$ post-dox exposure and tracked by FACS to determine the percent of cells positive for loop YFP. $(D)$ Sorted memory and non-memory cells were reinduced $3 \mathrm{~d}$ post-sort with dox, and FACS determined the percent of cells positive for loop YFP. $(E)$ Cells were exposed to TSA, dox, or TSA + dox to identify epigenetic silencing of the device. FACS determined the percent of cells positive for trigger RFP and loop YFP. $(A-E)$ Values represent mean $\pm S E ; n=3$.

exposed to dox to activate fluorophore expression, and cycloheximide was then added to inhibit protein biosynthesis. RFP and YFP degradation rates were determined to be approximately equivalent: 10.6 versus 11.5 arbitrary intensity units per hour, respectively (Supplemental Fig. S4). Thus, loop YFP protein persisted by positive feedback and not by protein stability. We concluded that MD10/TetOx2 was capable of recording dox exposure and transmitting memory of this response to progeny.

To investigate the independent behavior of memory and non-memory cells, cell sorting based on YFP expression was used to physically separate and expand the two cell populations for biological analysis. Over a period of 3 d, sorted memory cells behaved similarly to unsorted memory cells, in that the percentage that maintained loop expression decreased over time (Fig. 3C). Sorted memory cells were re-exposed $3 \mathrm{~d}$ post-sort to dox, at which time $20.2 \%$ were still expressing the loop, but only $83.3 \%$ reactivated the loop (Fig. 3D). Furthermore, sorted nonmemory cells largely failed to reinduce the loop (Fig. 3D). These observations suggested that epigenetic silencing might play a role in permanently deactivating the memory loop. To test this, trichostatin A (TSA) - a histone deacetylase inhibitor-was applied to unsorted MD10/ TetOx 2 cells before dox exposure to reverse gene silencing. While the number of cells expressing the trigger did not change, $12.5 \%$ more cells activated the memory loop if first exposed to TSA (Fig. 3E), indicating that decreased loop activity over time could be due to epigenetic silencing. This may also explain why only $42.7 \%$ of cells initially activated the loop. Every selected MD10/TetOx2 clone exhibited this behavior, suggesting that the loop became silenced during the selection process. Despite this effect, this cell line exhibits persistent inducible memory loop expression in a significant percentage of cells, allowing for tracking of the cellular response to dox through cell division.

\section{An integrated hypoxia memory device}

To track memory of hypoxia through cell division, the stable cell line MD15/HRE was constructed via random genomic integration of the HRE trigger and loop as a single plasmid. While $\mathrm{CoCl}_{2}$ induced a hypoxic response in transient experiments, it was not appropriate for longterm cell tracking due to its deleterious effect on cell viability and possible nonspecific activity as a hypoxia mimic. Alternatively, an anaerobic chamber caused less cell death and created an anoxic environment in which MD15/HRE could be easily characterized, since the HRE promoter is maximally active under anoxic conditions (Shibata et al. 2000). As fluorophores require $\mathrm{O}_{2}$ to fold properly, any trigger or loop protein produced during anoxia was not fluorescent, necessitating a recovery period before analysis. After $1 \mathrm{~d}$ of anoxic exposure and $1 \mathrm{~d}$ of recovery, the trigger was expressed in $21.5 \%$ of cells at a low intensity, since the anoxic response had likely subsided by that time, and the loop was activated in $10.8 \%$ of cells, as determined by FACS (Fig. 4A) and fluorescence microscopy (Fig. 4B). Loop-expressing cells were expected to have activated the trigger's anoxia-inducible promoter above the bistable threshold required for loop expression. A scatterplot of single-cell RFP versus YFP intensities post-anoxia shows that higher RFP expression corresponds to higher YFP expression, as measured by 
A

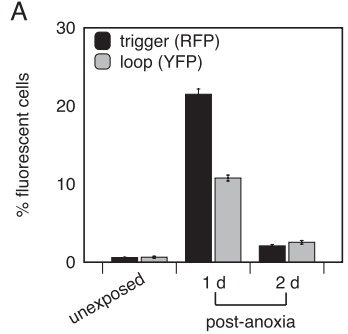

C

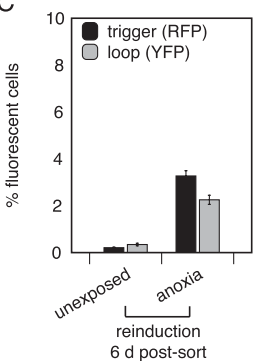

$\mathrm{F}$

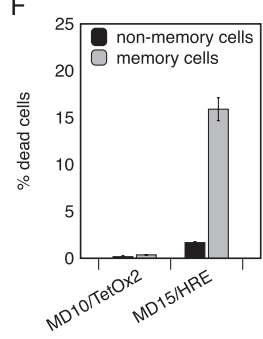

$\mathrm{G}$
B

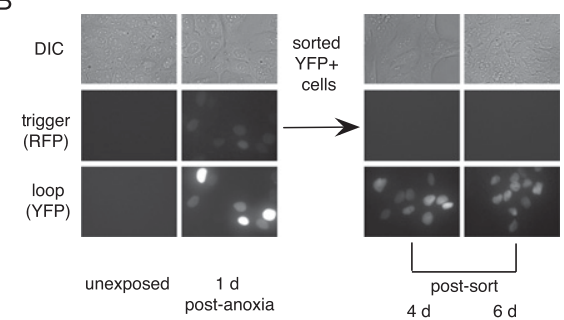

D 40 Q
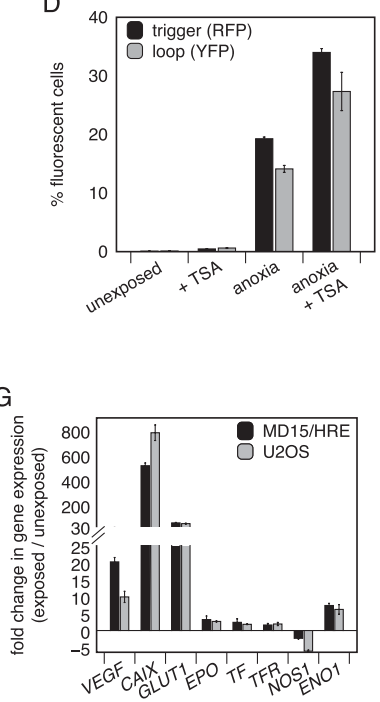

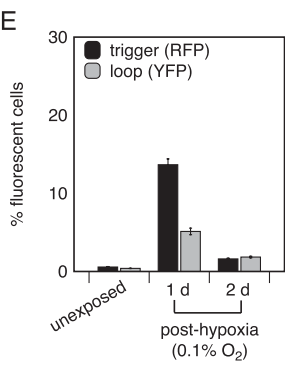

$\mathrm{H}$

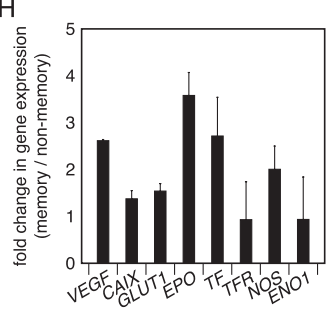

Figure 4. MD15/HRE device identifies a subpopulation with a unique memory of low $\mathrm{O}_{2}$ exposure. (A) Cells were exposed to anoxia and tracked by FACS for $2 \mathrm{~d}$. (B) Cells were exposed to anoxia and recovered for $1 \mathrm{~d}$. Memory cells (YFP+) were sorted and followed by microscopy for $6 \mathrm{~d}$. (C) Cells were exposed to anoxia and recovered for $1 \mathrm{~d}$. Nonmemory cells were sorted and re-exposed to anoxia $6 \mathrm{~d}$ post-sort. (D) Cells were exposed to TSA, anoxia, or TSA + anoxia to identify epigenetic silencing of the device. $(E)$ Cells were exposed to hypoxia and tracked by FACS for $2 \mathrm{~d}$. $(A, C, D, E)$ FACS determined the percent of cells positive for trigger RFP and loop YFP. Values represent mean $\pm \mathrm{SE}$; $n=$ 3. $(F)$ Cells were exposed to hypoxia and recovered for 1 d. MD10/TetOx2 was exposed to dox and recovered for $1 \mathrm{~d}$. Cell death was measured in memory versus non-memory cells by FACS. Values represent mean $\pm \mathrm{SE} ; n=3$. (G) $\mathrm{MD} 15 / \mathrm{HRE}$ and U2OS cells were exposed to hypoxia, and HIF target gene expression was measured. Values represent mean fold expression change over unexposed cells $\pm \mathrm{SE}$; $n=3$. $(H)$ Cells were exposed to hypoxia and recovered for $1 \mathrm{~d}$. Memory and non-memory cells were sorted, and HIF target gene expression was measured in each subpopulation. Values represent mean fold expression change in memory versus non-memory cells $\pm \mathrm{SE} ; n=2$.

FACS (Supplemental Fig. S5A). Thus, loop expression results from stronger trigger activation in response to anoxia.

During the first $2 \mathrm{~d}$ post-exposure, we observed a decrease in the memory subpopulation as a fraction of the total population (Fig. 4A). We hypothesized that memory cells, having activated a stronger response to anoxia, were likely more susceptible to growth defects and being diluted out of the population. This made it difficult to observe by FACS whether memory of anoxia indeed persisted through cell division in a subpopulation of cells (Supplemental Fig. S6). However, when memory cells were isolated from their non-memory counterparts via cell sorting and observed by fluorescence microscopy, a significant proportion of sorted memory cells expressed the loop for at least $6 \mathrm{~d}$ (about five generations) post-sort and grew in clusters, indicating active maintenance of memory through cell division (Fig. 4B).

To determine whether epigenetic silencing contributed to the observed decrease in the percentage of memory cells when the two subpopulations were cocultured, sorted non-memory cells were reinduced $6 \mathrm{~d}$ post-sort. Only $3.3 \%$ and $2.5 \%$ of sorted nonmemory cells reactivated the trigger and loop, respectively (Fig. 4C). In addition, when TSA was applied to unsorted MD15/HRE cells prior to anoxic exposure, $8.8 \%$ and $13.5 \%$ more cells activated the trigger and loop, respectively (Fig. 4D), indicating that epigenetic silencing was occurring in this cell line. We also noted that the slower growth of memory cells contributed to a decrease in the percentage of loop-expressing cells. When equal numbers of sorted memory and non-memory cells were plated $1 \mathrm{~d}$ post-exposure, memory cells exhibited a growth defect, reaching confluency $1 \mathrm{~d}$ later than non-memory cells (Supplemental Fig. S7A). This phenotype was not caused by synthetic gene expression, as no growth difference was observed between sorted MD10/ TetOx2 memory and non-memory cells (Supplemental Fig. S7B). In sum, epigenetic silencing and slow growth likely caused the observed decline in memory cells when memory and non-memory cells were cocultured.

To interrogate the biological relevance of the subpopulations captured by the circuit, hypoxia $\left(0.1 \% \mathrm{O}_{2}\right)$ was next used to activate the MD15/HRE device. While the trigger's HRE promoter is known to be less active under increasing $\mathrm{O}_{2}$ conditions, hypoxia is commonly used to mimic a tumor microenvironment and plays a significant biological role in disease and development (Bristow and Hill 2008). As expected, hypoxia activated the device in fewer cells (13.6\% trigger RFP-positive and 5.1\% loop YFP-positive) than anoxia, presumably due to the higher $\mathrm{O}_{2}$ concentration (Fig. 4E; Supplemental Fig. S5B). However, in cells that were activated, memory behavior similar to that under anoxic conditions was observed: Unsorted memory cells were quickly diluted out (Fig. 4E; Supplemental Fig. S6), while sorted memory cells grew in clonal populations for at least $8 \mathrm{~d}$ (about seven generations) (Supplemental Fig. S8). A viability assay using the dead cell stain SYTOX Blue (Invitrogen) revealed that memory 
Burrill et al.

cells remained less viable than non-memory cells $1 \mathrm{~d}$ posthypoxic exposure: $15.9 \%$ death versus $1.68 \%$ death, respectively, as compared with MD10/TetOx 2 memory and non-memory cells (Fig. 4F). This difference in viability not only contributed to dilution of the memory population over time, but was also indicative of memory and nonmemory subpopulations having distinct biological responses to hypoxia.

To investigate these responses, we first established that endogenous pathways responsive to low $\mathrm{O}_{2}$ concentrations were similarly functional in MD15/HRE and its background strain, U2OS. Both cell lines were exposed to hypoxia, and HIF target gene expression was measured by real-time PCR (Fig. 4G; Ke and Costa 2006). Since gene activation patterns were similar in both cell lines, we concluded that MD15/HRE responded to hypoxia with normal gene regulation. While this experiment examined hypoxic responses of the population as a whole, we next assessed whether expression of target genes was specifically up-regulated in memory cells, as compared with non-memory cells. Since memory cells had surpassed the circuit's bistable threshold for loop expression, they were expected to have responded more strongly to hypoxia. Memory and non-memory cells were sorted $1 \mathrm{~d}$ posthypoxic exposure, and HIF target gene expression was compared by real-time PCR (Fig. 4H). Indeed, a subset of HIF target genes was up-regulated in memory cells. Some target genes were not up-regulated, which was likely due to the fact that exposed cells needed to recover for $1 \mathrm{~d}$ for fluorophores to develop to allow for FACS analysis, during which time the initial transcriptional response to hypoxia subsided. Nevertheless, these results demonstrate that the synthetic circuit integrated in the cell line MD15/HRE is capable of sensing and tracking subpopulations that differ in their responses to hypoxia.

\section{An integrated DNA damage memory device}

To follow memory of DNA damage, the stable cell line MD12/p53R2-RE was generated via random genomic integration of the p53R2-RE trigger and loop as a single plasmid. While NCS was used as a DNA-damaging agent in transient experiments, it was not amenable to longterm cell tracking due to its highly deleterious effects on cell viability. Alternatively, a brief burst of $10 \mathrm{~J} / \mathrm{m}^{2}$ shortwave ultraviolet radiation (UV) allowed greater cell viability (Latonen et al. 2001; Sharma et al. 2010). UV exposure resulted in trigger and loop activation in $20.2 \%$ and $8.3 \%$ of cells, respectively, as determined by FACS (Fig. 5A), and higher trigger activation corresponded with greater loop activation (Supplemental Fig. S5C); this behavior was similar for all positive selected clones (Supplemental Fig. S9/. Fluorescence microscopy indicated that memory persisted for at least $2 \mathrm{~d}$ post-exposure in a subpopulation of cells (Fig. 5B); however, a significant decrease in the percentage of cells expressing the loop was observed during the first $2 \mathrm{~d}$ post-exposure.

While this characteristic precluded FACS analysis of sustained memory, fluorescence microscopy revealed that loop expression was maintained in small clonal populations
A
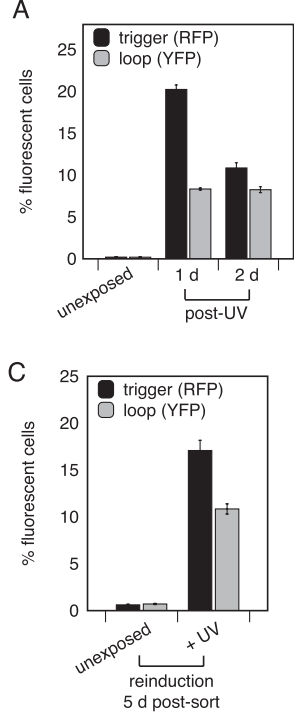

$\mathrm{F}$

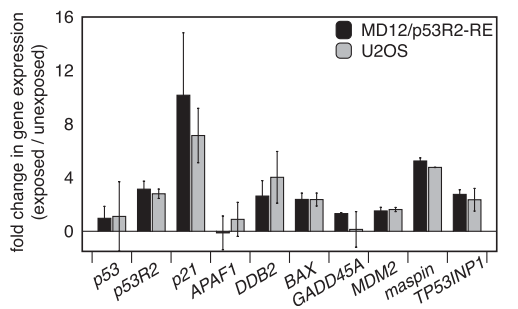

B
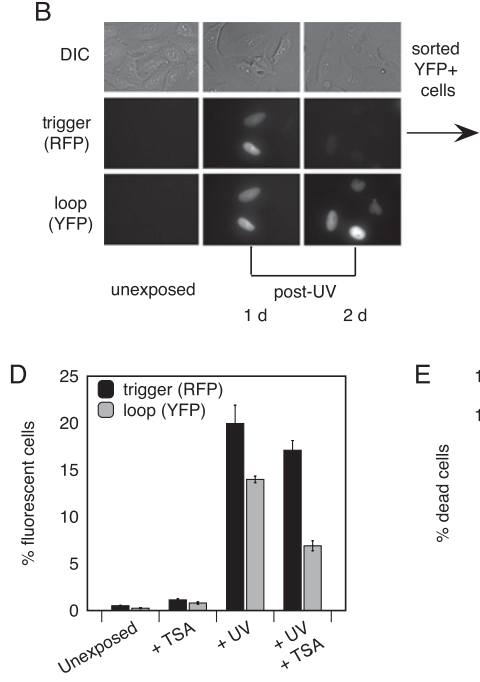

E

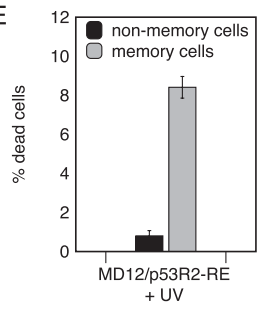

G

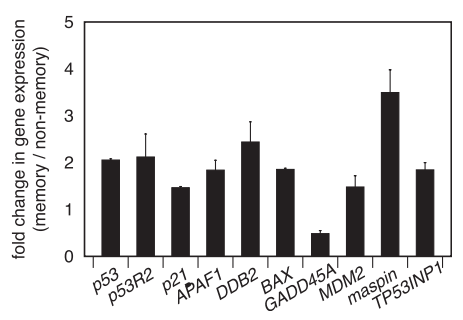

Figure 5. MD12/p53R2-RE device identifies a subpopulation with unique memory of DNA damage. (A) Cells were exposed to UV and tracked by FACS for $2 \mathrm{~d}$. (B) Cells were exposed to UV and recovered for $1 \mathrm{~d}$. Memory cells (YFP+) were sorted and followed by microscopy for $10 \mathrm{~d}$. $(C)$ Cells were exposed to UV and recovered for $1 \mathrm{~d}$. Non-memory cells were sorted and re-exposed to UV $5 \mathrm{~d}$ post-sort. $(D)$ Cells were exposed to TSA, UV, or TSA + UV to identify epigenetic silencing of the device. $(A, C, D)$ FACS determined the percent of cells positive for trigger RFP and loop YFP. Values represent mean \pm $\mathrm{SE} ; n=3$. $(E)$ Cells were exposed to UV and recovered for $2 \mathrm{~d}$. Cell death was measured in memory versus non-memory cells by FACS. Values represent mean $\pm \mathrm{SE}$; $n=3$. $(F) \mathrm{MD} 12 / \mathrm{p} 53 \mathrm{R} 2-\mathrm{RE}$ and $\mathrm{U} 2 \mathrm{OS}$ cells were exposed to UV, and p53 target gene expression was measured. Values represent mean fold expression change over unexposed cells $\pm \mathrm{SE}$; $n=3$. $(G)$ Cells were exposed to UV and recovered for $1 \mathrm{~d}$. Memory and non-memory cells were sorted, and p53 target gene expression was measured in each subpopulation. Values represent mean fold expression change in memory versus non-memory cells $\pm \mathrm{SE}_{;} n=2$. 
when memory cells were isolated $2 \mathrm{~d}$ post-UV exposure (Fig. 5B; Supplemental Fig. S6). The loop was expressed in a subpopulation of cells for at least $10 \mathrm{~d}$ (about eight generations) post-sort. This indicated that a subpopulation successfully activated the device above the bistable threshold for loop expression, permitting tracking of memory and non-memory cells. Gene dysfunction was not a contributing factor to the observed memory population decrease, as sorted non-memory cells were able to reinduce both the trigger and loop to levels comparable with their initial induction (Fig. 5C). Furthermore, epigenetic silencing of the device did not likely affect its function over time: Exposure to TSA alone caused no significant induction of the device, and pretreatment with TSA did not increase the number of cells that responded to subsequent UV exposure (Fig. 5D).

These results implied that the proportion of memory cells-having executed a stronger DNA damage responsedecreased post-damage due to a growth defect or cell death, resulting in dilution of the population over time by the more rapidly growing or viable non-memory cells. When equal numbers of sorted memory and non-memory cells were plated and observed for $4 \mathrm{~d}$ by fluorescence microscopy, non-memory cells reached confluency $2 \mathrm{~d}$ sooner than memory cells (Supplemental Fig. S7C). This slow growth phenotype could account for memory cells being diluted out of the population over time when memory and non-memory cells are grown together. Using the dead cell stain SYTOX Blue, we also determined that memory cells were less viable than non-memory cells $2 \mathrm{~d}$ post-UV exposure: $8.4 \%$ cell death versus $0.8 \%$, respectively (Fig. $5 E)$. Altogether, these data suggest that memory and nonmemory cells maintained different growth and viability phenotypes after UV exposure.

We next asked whether unique gene expression profiles characterized how distinct subpopulations responded initially to DNA damage. Endogenous response pathways were similarly functional in MD12/p53R2-RE and its background strain post-UV exposure, as measured by p53 target gene expression using real-time PCR (Fig. 5F; Brady and Attardi 2010). Furthermore, a subset of target genes was specifically up-regulated in memory cells (Fig. 5G). Memory and non-memory subpopulations were sorted $1 \mathrm{~d}$ post-UV exposure, and p53 target gene expression was compared by real-time PCR. Since exposed cells required $1 \mathrm{~d}$ of recovery before sorting, not all target genes were up-regulated at the indicated time point. In sum, these results verify that the synthetic circuit is capable of differentiating between subpopulations that uniquely respond to DNA damage.

To assess whether specific initial responses translated into each subpopulation maintaining distinct long-term expression profiles, we performed gene expression profiling of memory and non-memory cells multiple days after UV exposure. After $3 \mathrm{~d}$ of recovery from UV treatment, memory and non-memory cells were sorted. The expression signature of memory cells was distinct from their non-memory counterparts: 127 genes were up-regulated and 31 genes were down-regulated in memory cells (fold change $\geq 2.0$, corrected $P$-value $\leq 0.05$ ) (Supplemental File S2). Bioinformatics analysis identified the transcrip- tional pattern of oxidative stress and general stress responses in memory cells (Fig. 6A): Up-regulated genes were enriched for those responsive to external stimulus $(P=1.48 \times$ $\left.10^{-3}\right)$, wounding $\left(P=1.56 \times 10^{-3}\right)$, hydrogen peroxide $\left(P=3.41 \times 10^{-3}\right)$, stress $\left(P=3.89 \times 10^{-3}\right)$, reactive oxygen species $(\mathrm{ROS})\left(P=6.05 \times 10^{-3}\right)$, and chemical stimulus $(P=$ $9.29 \times 10^{-3}$ ). Enrichments were validated by real-time PCR (Supplemental Fig. S10A). To eliminate any transcriptional effects caused by expression of a synthetic device, profiling of MD10/TetOx2 sorted memory versus nonmemory cells was also performed, and common genes were removed from the MD12/p53R2-RE data analysis (Supplemental Fig. S10B; Supplemental File S2).

While the microarray data defined a set of genes that were uniquely expressed in memory cells multiple days post-DNA damage, it did not inform on the expression level of those genes at earlier time points. To address this question, we tested the expression of four up-regulated genes-CDNF, MAX dimerization protein 1 (MXD1), SCL39A2, and GRK5-1 d after UV exposure (Fig. 6B). Interestingly, all four tested genes showed significant upregulation in memory cells, as compared with non-memory cells. Thus, these genes were expressed both $1 \mathrm{~d}$ and $3 \mathrm{~d}$ after UV exposure. This suggested that UV-mediated DNA damage produced a transcriptional response that was maintained over time in memory and non-memory cells. Since differences in not only gene expression, but also viability and growth, were shown to persist for multiple days, we concluded that the MD12/p53R2-RE circuit is capable of capturing subpopulations with distinct long-term memories of DNA damage.

\section{Discussion}

\section{Building a prototype memory circuit} in mammalian cells

In this study, we present the successful engineering and implementation of synthetic memory devices in human cells. The construction of a prototype, dox-inducible circuit (MD10/TetOx2) revealed behavioral qualities of an integrated, transcription-based device that could inform further applied systems. In all isolated clones, most cells activated the trigger in response to dox, and a significant
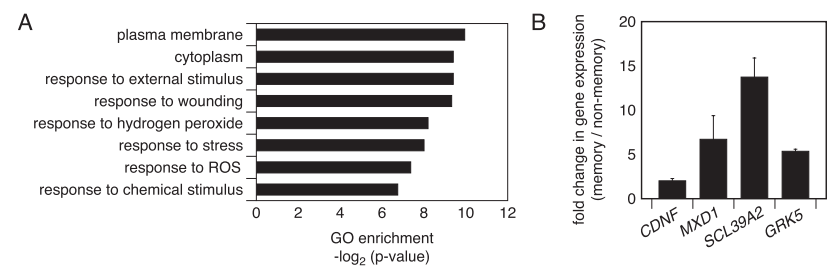

Figure 6. MD12/p53R2-RE device identifies a subpopulation with a unique transcriptional profile. (A) Gene ontology enrichment of genes up-regulated in memory cells $3 \mathrm{~d}$ post-UV exposure. (B) Cells were exposed to UV and recovered for $1 \mathrm{~d}$. Memory and non-memory cells were sorted, and gene expression was measured in each subpopulation. Values represent mean fold expression change in memory versus non-memory cells $\pm \mathrm{SE} ; n=2$. 
fraction activated the memory loop. Moreover, a subpopulation of loop-expressing cells transmitted the memory protein to daughter cells for multiple generations. These cells likely activated the circuit above its bistable threshold. The MD10/TetOx2 circuit provides one of the first synthetic examples of what is required to create a bistable mammalian memory switch based on positive feedback.

While a significant percentage of cells maintained loop expression post-exposure, this population decreased over time. Indeed, time-lapse fluorescence microscopy revealed that some daughter cells failed to inherit memory protein from loop-expressing mother cells. As this was observed for all selected clones, the genomic integration location was unlikely to be causative. However, we hypothesize that epigenetic silencing resulted in memory loop deactivation, and stochastic noise in memory loop protein segregation during cell division might also have played a role. If a daughter cell randomly fails to receive a sufficient amount of loop protein to maintain feedback, it will switch to a non-memory state that is propagated in future progeny. This behavior has been observed for both natural and synthetic transcriptional autoregulatory circuits (Becskei et al. 2001; Weinberger and Shenk 2007; To and Maheshri 2010). Producing more loop protein before cell division, by either increasing the synthesis rate or reducing the rate of cell division, is expected to minimize any loss of memory over time (Ajo-Franklin et al. 2007). However, for certain uses-such as drug dosage in a clinical setting-short-term memory loop expression could be desirable.

Integrating synthetic circuits with endogenous pathways

To demonstrate its potential to report on biological phenomena, the MD10/TetOx2 device was reconfigured to respond to endogenous hypoxia and DNA damage response pathways. Memory cells were identified as descendants of cells that experienced HIF-1 or p53R2 activity above the circuit's bistable threshold, while non-memory cells were those that responded more weakly, such that the loop was not activated. The formation and defining characteristics of these memory cells, versus their non-memory counterparts, could vary depending on cell state, DNAdamaging or hypoxic agents, length of exposure, and time of recovery. Furthermore, a given stressor likely produces many subpopulations with uniquely protracted responses. Our goal was to use the described circuits to identify how an initial response translated into sustained biological characteristics that distinguished what we defined as memory and non-memory cell subpopulations.

Interestingly, the hypoxia and DNA damage memory devices behaved quite differently from the dox memory device. MD10/TetOx2 responded to dox by activating the trigger to similar levels in all cells and the memory loop to similar levels in $42.7 \%$ of cells (Supplemental Fig. S2). In contrast, MD15/HRE and MD12/p53R2-RE responded to hypoxia or DNA damage with variable activation of the trigger and loop (Supplemental Fig. S5). Furthermore, while memory of dox exposure was sustained in a signif- icant number of cells, memory of hypoxia and DNA damage persisted in a small subset.

Behavioral differences were likely due to the more heterogeneous activation of hypoxia and DNA damage signaling pathways. MD10/TetOx2 induction occurs when the tet repressor can no longer bind the trigger's promoter due to the presence of dox, resulting in strong, homogeneous trigger and loop expression (Supplemental Fig. S2). In contrast, MD15/HRE and MD12/p53R2-RE activation is dependent on signals transduced by biological pathways composed of numerous proteins, each with its own degree of biological noise. Unlike the dox-inducible trigger, HIF-1 and p53 should not be uniformly activated within a population (Bristow and Hill 2008; MurrayZmijewski et al. 2008), resulting in heterogeneous trigger and loop activation (Supplemental Fig. S5). MD15/ HRE and MD12/p53R2-RE thus permit the isolation of unique subpopulations after hypoxia or DNA damage.

The utility of the hypoxia and DNA damage memory devices in detecting biologically distinct subpopulations was assessed in multiple ways. We determined that in initial response to hypoxia or UV, HIF and p53 target gene expression was elevated in MD15/HRE and MD12/p53R2$\mathrm{RE}$ cells that activated both the trigger and loop, as compared with cells that only activated the trigger. This result indicated that the devices work as intended: Cells with a stronger response are capable of overcoming the bistable threshold of the circuit, such that the loop is expressed. We also established that a stronger response translated into long-term phenotypes, including slow growth and poor viability. Memory cells exhibited these characteristics for multiple generations past the point of exposure, as compared with their non-memory counterparts.

Finally, gene expression profiling revealed that DNAdamaged memory cells had a persistent gene expression signature that was different from that of non-memory cells. The memory cell expression profile was largely enriched for genes responsive to oxidative stress, as well as stress in general, including DNA damage-inducible transcript (DDIT3), glutathione peroxidase 3 (GPX3), MXD1, egl nine homolog 3 (EGLN3), and tumor protein p53inducible nuclear protein 1 (TP53INP1). UV radiation is known to cause significant intracellular production of ROS and reactive nitrogen species as well as alter the levels of intracellular antioxidant enzymes (Zhang et al. 1997; BirchMachin and Swalwell 2010). Our study shows that transcriptional responses to UV-induced oxidative damage persist through multiple generations in a subpopulation of cells. It is possible that this differential maintenance of gene expression translates into differences in vulnerability to future damage or disease and may also dictate the mechanisms by which each subpopulation protects the fate of its progeny.

\section{Conclusions}

The memory devices presented here have the potential to illuminate previously undescribed biological phenomena. The hypoxia and DNA damage memory circuits could be used in further analyses, such as deep-sequencing or 
epigenetic mapping, of differentially responsive subpopulations to create a more detailed picture of how a cell's history contributes to its biological future. Differentially regulated genes in memory cells could potentially serve as targets in future work toward defining how the inherited expression profile is maintained. This approach could implicate genes that play a role in disease development. The work might also be translated to a xenograft model in mice to study the in vivo heterogeneous effects of DNA damage and hypoxia through the development of a solid tumor. It would be interesting to identify whether these transient stimuli produce subpopulations that are more or less prone to disease development. Given their modular nature, the circuits could potentially produce outputs other than fluorophores. For example, in the future, a memory device could be used in a clinical setting by modifying the loop to produce a therapeutic drug in response to a transient stimulus. The loop could also be altered to create a useful tissue-engineering tool that produces morphogens or growth factors for differentiation control in tissue engineering. While these proposed applications will require significant retooling and testing of the device, their pursuit will help advance and define the utility of synthetic circuits.

Our work demonstrates that complex biological problems can be investigated with synthetic circuits. To date, development of new synthetic devices has been hindered by a slow design cycle and poor device robustness, particularly in mammalian cell culture (Burrill et al. 2011). Streamlining the mammalian design cycle is critical as synthetic biology strives to better integrate with complex human applications such as stem cell therapy and tissue engineering. Continuing to build mammalian devices will undoubtedly provide invaluable data for more comprehensive quantitative models, which will allow better predictions of function at the preliminary design stage and thereby reduce the number of tested iterations of a device. Synthetic devices destined for clinical applications must also demonstrate faithful performance; constructing genomically integrated devices, as with our memory circuits, is an important first step. Improving mammalian cell design remains an essential task for synthetic biology as the field continues to engage in the engineering of increasingly complex cell types.

\section{Materials and methods}

\section{Plasmid constructs}

Escherichia coli DH5 $\alpha$ was used for all plasmid manipulations. Bacteria were grown in LB-ampicillin medium to maintain plasmids; if engineered constructs contained synthetic ZFs, medium was supplemented with $0.02 \mathrm{mM}$ zinc chloride. DNA fragments with universal cloning sites (EcoRI, NotI, XbaI, SpeI, and PstI) were generated by PCR and assembled via BioBrick DNA assembly (Phillips and Silver 2006).

A CMV-TetOx2 promoter fragment (from pcDNA5/FRT/TO, Invitrogen) ligated in front of a human kozak sequence produced a dox-inducible promoter. A HRE promoter was provided by the Brown laboratory (Shibata et al. 2000). Response elements from the human p53R2 gene (Ohno et al. 2008) were constructed as annealed oligos (Integrated DNA Technologies) and ligated in front a minimal promoter (Shibata et al. 2000) to generate a p53R2RE promoter. Human codon-optimized synthetic ZFs (Hurt et al. 2003) were commercially synthesized by Mr. Gene GmbH.

For transient transfections, triggers and reporters were cloned as NotI/SpeI fragments into the Flp-In T-REx vector in which the constitutive CMV promoter was deleted (Invitrogen, Silver Laboratory). For MD10/TetOx2 (clone MD10.21), trigger and memory loop genes were cloned as separate fragments into a pcDNA3.1 (+)-based vector (Invitrogen) in which the neomycin resistance marker was replaced with hygromycin or puromycin resistance, respectively, and the constitutive CMV promoter was deleted (Silver Laboratory). For MD15/HRE (clone 15.21) and MD12/p53R2-RE (clone 12.34), trigger and loop genes were cloned as one fragment into the puromycin-resistant pcDNA3.1 (+)-based vector (Invitrogen, Silver Laboratory).

\section{Memory device design strategy}

Devices were built in two stages. First, multiple gene circuits were designed and tested via transient transfection. In these plasmid-based experiments, multiple designs were characterized to identify elements that generated the most effective circuit activation and least basal activity. Selected prototypes were then genomically integrated to produce the final stable devices, which are characterized in greater detail in this study.

\section{Cell culture and transfection}

Plain U2OS and U2OS Flp-In T-REx cells (Blacklow Laboratory) were grown in McCoy's 5A medium supplemented with $10 \%$ tetracycline-screened fetal bovine serum (FBS) and $1 \%$ penicillin and streptomycin; T-REx cells were further supplemented with $15 \mu \mathrm{g} / \mathrm{mL}$ blasticidin and $200 \mu \mathrm{g} / \mathrm{mL}$ zeocin. Cells were grown at $37^{\circ} \mathrm{C}$ in a humidified $\mathrm{CO}_{2}$ incubator.

Transient transfections were performed by plating $1.2 \times 10^{5}$ cells per well in 12-well culture dishes and transfecting with $800 \mathrm{ng}$ of total plasmid DNA and $2 \mu \mathrm{L}$ of Lipofectamine 2000 (Invitrogen) in $1 \mathrm{~mL}$ of antibiotic-free medium (Supplemental Table S1). Medium was changed $4 \mathrm{~h}$ post-transfection, and cells were exposed $20 \mathrm{~h}$ later to $1 \mu \mathrm{g} / \mathrm{mL}$ dox (Sigma-Aldrich), $0.5 \mu \mathrm{g} /$ $\mathrm{mL}$ NCS (Sigma-Aldrich), or $100 \mu \mathrm{M} \mathrm{CoCl}_{2}$ (Sigma-Aldrich) for $24 \mathrm{~h}$ and analyzed by FACS.

Stable cell lines were generated by plating $3.0 \times 10^{5}$ cells per well in six-well culture dishes and transfecting with $2 \mu \mathrm{g}$ of plasmid DNA and $5 \mu \mathrm{L}$ of Lipofectamine 2000 in $2 \mathrm{~mL}$ of antibiotic-free medium. Medium was changed $4 \mathrm{~h}$ post-transfection, and cells were exposed to selection medium the following day (Supplemental Table S2). After $5 \mathrm{~d}$ of selection, medium was changed to maintenance antibiotic concentrations (Supplemental Table S2). Clones were picked and screened for inducible expression via $1 \mu \mathrm{g} / \mathrm{mL}$ dox, $0.5 \mu \mathrm{g} / \mathrm{mL} \mathrm{NCS}$, or 100 $\mu \mathrm{M} \mathrm{CoCl}$. Positive clones were expanded and maintained as stable lines.

\section{Induction of MD15/HRE and MD12/p53R2-RE cell lines}

To analyze MD15/HRE behavior, $3.0 \times 10^{6}$ cells were plated in $10-\mathrm{cm}$ plates. The following day, plates were exposed to anoxia $\left(0 \% \mathrm{O}_{2}, \sim 2.0 \% \mathrm{H}_{2}\right)$ in an anaerobic chamber (Wyss Institute for Biologically Inspired Engineering) for $1 \mathrm{~d}$ in $\mathrm{CO}_{2}$-independent medium (Invitrogen) or hypoxia $\left(0.1 \% \mathrm{O}_{2}, 5.0 \% \mathrm{CO}_{2}\right)$ in a hypoxic chamber (Kaelin laboratory, Dana Farber Cancer Institute). When cells were returned to normoxia, the medium was replaced with the appropriate maintenance medium. To analyze MD12/p53R2-RE behavior, $3.0 \times 10^{5}$ cells per well were plated 
in six-well plates. The following day, plates were exposed to a brief burst of $10 \mathrm{~J} / \mathrm{m}^{2} \mathrm{UV}$ (Lahav laboratory, Harvard Systems Biology).

\section{Flow cytometry and cell sorting}

Prior to FACS analysis, cells were fixed in $4 \%$ paraformaldehyde/ $1 \times$ PBS solution for $10 \mathrm{~min}$, resuspended in $200 \mu \mathrm{L}$ of $1 \times$ PBS, and stored at $4{ }^{\circ} \mathrm{C}$. Cells were later loaded in 96-well plates or 5-mL polystyrene tubes (BD Biosciences) on an LSRII (BD Biosciences) with 488-nm (DsRed) and 568-nm (Fitc) lasers (Harvard Systems Biology). Cells $\left(1.0 \times 10^{4}\right)$ were analyzed for RFP (DsRed) and YFP (FITC) fluorescence and gated based on cell size and granularity. Unexposed cells controlled for basal fluorophore expression. Data were analyzed using FlowJo software.

To sort MD10/TetOx2 cells, three six-well plates were exposed to dox, washed with $1 \times$ PBS, and moved to three T-150 flasks for $2 \mathrm{~d}$. Cells were then trypsinized, spun at $1100 \mathrm{rpm}$ for 5 min, washed with $1 \times$ PBS, spun a second time, resuspended in 3 $\mathrm{mL}$ of $1 \times \mathrm{PBS} / 1 \% \mathrm{FBS}$, and filtered. To sort MD12/p53R2-RE cells, 12 six-well plates were exposed to UV and recovered for $2 \mathrm{~d}$. Cells were then processed as described above, except that four six-well plates of cells were pooled to produce three replicates. To sort MD15/HRE cells, nine $10-\mathrm{cm}$ plates were exposed to anoxia or hypoxia and recovered for $1 \mathrm{~d}$. Cells were then processed as described above, except that three $10-\mathrm{cm}$ plates were pooled to produce three replicates.

Processed cells were run on a FACS Aria II with a $100 \mu \mathrm{M}$ nozzle at 20 psi (Harvard Systems Biology). Excitation optics for RFP consisted of a 75-mW 594-nm laser; detection optics included a 630/22 bandpass filter. Excitation optics for YFP consisted of a $15-\mathrm{mW} 488-\mathrm{nm}$ laser; detection optics included a 520-nm longpass dichroic mirror and a 530/30 bandpass filter. For microscopy, $2.0 \times 10^{5}$ memory and non-memory cells were sorted. Sorted MD10/TetOx2 and sorted MD15/HRE cells were seeded in 12-well dishes; sorted MD12/p53R2-RE cells were seeded in 24-well dishes.

\section{Fluorescence microscopy}

For short-term microscopy, cells were imaged at $20 \times$ with a Nikon TE2000-E inverted fluorescence microscope equipped with a Hamamatsu ORCA-ER camera and HcRed (RFP) and JP2 (YFP) filters (Silver Laboratory). Images were acquired and analyzed using Metamorph software.

For long-term imaging, $5.0 \times 10^{4}$ cells per well were seeded in a 12-well glass-bottom culture dish (MatTek) and exposed to dox for $1 \mathrm{~d}$. Wells were next washed with medium. Cells were allowed to recover for $1 \mathrm{~d}$ and then imaged every hour for $3 \mathrm{~d}$ using a Plan Apo $20 \times 0.75$ NA objective lens on a Nikon TE200E motorized inverted microscope equipped with a Hamamatsu ORCA-ER cooled CCD camera; Prior Proscan II motorized stage and shutters; EXFO X-cite 120-XL fluorescence illuminator; a $37^{\circ} \mathrm{C}$, $5 \% \mathrm{CO}_{2}$ custom-built microscope enclosure incubation chamber; and mCherry (RFP) and YFP filter sets (Nikon Imaging Center, Harvard Medical School). Images were acquired and analyzed using Metamorph software.

\section{Cycloheximide assay}

MD10/TetOx2 cells were plated in 12-well dishes and exposed to dox in triplicate. After $24 \mathrm{~h}$ of incubation, cells were exposed to $100 \mu \mathrm{M}$ cycloheximide (Sigma-Aldrich) for $8 \mathrm{~h}$. Three wells were fixed in $4 \%$ PFA/ $1 \times$ PBS per hour and later analyzed by FACS. The same procedure was applied to regular T-REx cells.

\section{Histone deacetylase inhibitor assay}

MD10/TetOx2 cells were plated in 12-well dishes, MD12/ p53R2-RE cells were plated in six-well dishes, and MD15/HRE cells were plated in 10-cm plates. Cells were exposed in triplicate to $50 \mathrm{ng} / \mathrm{mL}$ TSA (Sigma-Aldrich) for $16 \mathrm{~h}$ and then washed and exposed in triplicate to dox, UV, or anoxia. Three wells were fixed in $4 \%$ PFA/1 $\times$ PBS and later analyzed by FACS.

\section{SYTOX Blue assay}

MD15/HRE cells were plated in 10-cm plates, were exposed to hypoxia, and recovered for $1 \mathrm{~d}$. MD10/TetOx2 cells were plated in six-well plates, were exposed to dox, and recovered for $1 \mathrm{~d}$. MD12/p53R2-RE cells were plated in six-well plates, were exposed to UV, and recovered for $2 \mathrm{~d}$. To analyze viability, cells were trypsinized, spun at $1100 \mathrm{rpm}$ for $5 \mathrm{~min}$, and resuspended in $10 \mathrm{~mL}$ of $1 \times$ PBS. Five hundred microliters from each plate was stained with $1 \mu \mathrm{M}$ SYTOX Blue dead cell stain (Invitrogen), incubated for $5 \mathrm{~min}$, and analyzed by FACS using the AmCyan filter. Unexposed cells were treated similarly to control for basal levels of cell death.

\section{Endogenous pathway induction}

MD15/HRE and MD12/p53R2-RE were plated and exposed to UV or hypoxia, respectively. Whole-cell RNA was extracted using the RNeasy minikit (Qiagen), and cDNA was prepared using the SuperScript III first strand synthesis system (Invitrogen). Unexposed cells served as controls for background expression.

\section{Gene expression profiling}

MD10/TetOx2 and MD12/p53R2-RE cells were plated in sixwell plates; exposed to dox or UV in triplicate, respectively; and allowed to recover for $3 \mathrm{~d}$. Cells were then processed as described above for cell sorting. For each biological replicate, $2.0 \times 10^{5}$ memory and non-memory cells were sorted, and RNA was extracted using the RNeasy minikit (Qiagen). cDNA was prepared, biotinylated, and hybridized to Gene 1.0 ST arrays (Affymetrix). Arrays were scanned and quantified according to standard Affymetrix protocols at the Dana Farber Microarray Core Facility (Dana Farber Cancer Institute). Data sets have been submitted to the Gene Expression Omnibus database (record GSE38189).

\section{Identification and analysis of differentially regulated genes}

Data were annotated and normalized by RMA analysis using Affymetrix Expression Console software. Differential gene expression was determined using the MATLAB Bioinformatics Toolbox (MathWorks). $P$-values were calculated using a permutation $t$-test of $1.0 \times 10^{4}$ permutations. Genes with a fold change $\geq 2$ and $P$-value $\leq 0.05$ were considered differentially expressed and analyzed for gene ontology enrichment via GoStat (http:// gostat.wehi.edu.au), with Benjamini correction for multiple hypothesis testing; enrichment was considered significant with $P \leq 0.01$. Differentially expressed genes were validated by realtime PCR using $0.5 \mu \mathrm{g}$ of RNA of specified cell populations. Primers amplified $\sim 100$ base pairs (Supplemental Table S3). Differential expression was normalized to the human gene $A C T B$.

\section{Acknowledgments}

We owe special thanks to D. Drubin for initiating this project. We further thank D. Ducat, C. Agapakis, Q. Wang, K. Haynes, J. Lohmueller, T. Armel, E. Wintermute, W. Senapedis, the Lahav 
laboratory (Harvard Systems Biology), C. Shen, W. Kaelin, J. Way, $\mathrm{K}$. Joung, and J. Hurt for thoughtful contributions to this manuscript and sharing reagents. Technical expertise was generously provided by J. Moore and A. Kressler (Harvard Systems Biology Flow Cytometry Facility), the Dana Farber Cancer Institute Microarray Core and Flow Cytometry Core, and J. Waters and L. Piedmont (Nikon Imaging Center at Harvard Medical School). D.R.B. is supported by the National Science Foundation (NSF) Synthetic Biology Engineering Research Center (SynBERC), M.C.I. is supported by the Natural Sciences and Engineering Research Council of Canada, P.M.B. is supported by the Harvard University Center for the Environment and NSF SynBERC, and P.A.S. is supported by the National Institutes of Health, the Wyss Institute for Biologically Inspired Engineering, and the Defense Advanced Research Projects Agency.

\section{References}

Acar M, Mettetal JT, van Oudenaarden A. 2008. Stochastic switching as a survival strategy in fluctuating environments. Nat Genet 40: 471-475.

Ajo-Franklin CM, Drubin DA, Eskin JA, Gee EPS, Landgraf D, Phillips I, Silver PA. 2007. Rational design of memory in eukaryotic cells. Genes Dev 21: 2271-2276.

Avery SV. 2006. Microbial cell individuality and the underlying sources of heterogeneity. Nat Rev Microbiol 4: 577-587.

Becskei A, Séraphin B, Serrano L. 2001. Positive feedback in eukaryotic gene networks: Cell differentiation by graded to binary response conversion. EMBO J 20: 2528-2535.

Beerli RR, Segal DI, Dreier B, Barbas CF. 1998. Toward controlling gene expression at will: Specific regulation of the erbB-2/ HER-2 promoter by using polydactyl zinc finger proteins constructed from modular building blocks. Proc Natl Acad Sci 95: 14628-14633.

Birch-Machin MA, Swalwell H. 2010. How mitochondria record the effects of UV exposure and oxidative stress using human skin as a model tissue. Mutagenesis 25: 101-107.

Bishop AL, Rab FA, Sumner ER, Avery SV. 2006. Phenotypic heterogeneity can enhance rare-cell survival in 'stress-sensitive' yeast populations. Mol Microbiol 63: 507-520.

Bonnet J, Subsoontorn P, Endy D. 2012. Rewritable digital data storage in live cells via engineered control of recombination directionality. Proc Natl Acad Sci 109: 8884-8889.

Boshart M, Weber F, Jahn G, Dorsch-Häsler K, Fleckenstein B, Schaffner W. 1985. A very strong enhancer is located upstream of an immediate early gene of human cytomegalovirus. Cell 41: 521-530.

Brady CA, Attardi LD. 2010. p53 at a glance. J Cell Sci 123: 2527-2532.

Bristow RG, Hill RP. 2008. Hypoxia and metabolism. Hypoxia, DNA repair and genetic instability. Nat Rev Cancer 8: 180-192.

Burrill DR, Silver PA. 2010. Making cellular memories. Cell 140: $13-18$.

Burrill DR, Silver PA. 2011. Synthetic circuit identifies subpopulations with sustained memory of DNA damage. Genes Dev 25: 434-439.

Burrill DR, Boyle PM, Silver PA. 2011. A new approach to an old problem: Synthetic biology tools for human disease and metabolism. Cold Spring Harb Symp Quant Biol doi: 10.1101/sqb.2011.76.010686.

Chen H, Yan Y, Davidson TL, Shinkai Y, Costa M. 2006. Hypoxic stress induces dimethylated histone H3 lysine 9 through histone methyltransferase G9a in mammalian cells. Cancer Res 66: 9009-9016.

Denko NC. 2008. Hypoxia, HIF1 and glucose metabolism in the solid tumour. Nat Rev Cancer 8: 705-713.
Forni PE, Scuoppo C, Imayoshi I, Taulli R, Dastrù W, Sala V, Betz UAK, Muzzi P, Martinuzzi D, Vercelli AE, et al. 2006. High levels of Cre expression in neuronal progenitors cause defects in brain development leading to microencephaly and hydrocephaly. I Neurosci 26: 9593-9602.

Haynes KA, Silver PA. 2009. Eukaryotic systems broaden the scope of synthetic biology. J Cell Biol 187: 589-596.

Hurt JA, Thibodeau SA, Hirsh AS, Pabo CO, Joung JK. 2003. Highly specific zinc finger proteins obtained by directed domain shuffling and cell-based selection. Proc Natl Acad Sci 100: 12271-12276.

Kalderon D, Roberts BL, Richardson WD, Smith AE. 1984. A short amino acid sequence able to specify nuclear location. Cell 39: 499-509.

Ke Q, Costa M. 2006. Hypoxia-inducible factor-1 (HIF-1). Mol Pharmacol 70: 1469-1480.

Latonen L, Taya Y, Laiho M. 2001. UV-radiation induces dosedependent regulation of p53 response and modulates p53HDM2 interaction in human fibroblasts. Oncogene 20: 6784-6793.

Lee SH, Kim J, Kim W-H, Lee YM. 2009. Hypoxic silencing of tumor suppressor RUNX3 by histone modification in gastric cancer cells. Oncogene 28: 184-194.

Lu Y, Chu A, Turker MS, Glazer PM. 2011. Hypoxia-induced epigenetic regulation and silencing of the BRCA1 promoter. Mol Cell Biol 31: 3339-3350.

Murray-Zmijewski F, Slee EA, Lu X. 2008. A complex barcode underlies the heterogeneous response of p53 to stress. Nat Rev Mol Cell Biol 9: 702-712.

Ohno K, Ishihata K, Tanaka-Azuma Y, Yamada T. 2008. A genotoxicity test system based on p53R2 gene expression in human cells: Assessment of its reactivity to various classes of genotoxic chemicals. Mutat Res Genet Toxicol Environ Mutagen 656: 27-35.

Phillips IE, Silver PA. 2006. A new biobrick assembly strategy designed for facile protein engineering. http://hdl.handle.net/ 1721.1/32535.

Shaner NC, Campbell RE, Steinbach PA, Giepmans BNG, Palmer $\mathrm{AE}$, Tsien RY. 2004. Improved monomeric red, orange and yellow fluorescent proteins derived from Discosoma sp. red fluorescent protein. Nat Biotechnol 22: 1567-1572.

Shaner NC, Steinbach PA, Tsien RY. 2005. A guide to choosing fluorescent proteins. Nat Methods 2: 905-909.

Sharma SV, Lee DY, Li B, Quinlan MP, Takahashi F, Maheswaran S, McDermott U, Azizian N, Zou L, Fischbach MA, et al. 2010. A chromatin-mediated reversible drug-tolerant state in cancer cell subpopulations. Cell 141: 69-80.

Shibata T, Giaccia AJ, Brown JM. 2000. Development of a hypoxia-responsive vector for tumor-specific gene therapy. Gene Ther 7: 493-498.

Spiller DG, Wood CD, Rand DA, White MRH. 2010. Measurement of single-cell dynamics. Nature 465: 736-745.

Tanaka H, Arakawa H, Yamaguchi T, Shiraishi K, Fukuda S, Matsui K, Takei Y, Nakamura Y. 2000. A ribonucleotide reductase gene involved in a p53-dependent cell-cycle checkpoint for DNA damage. Nature 404: 42-49.

To TL, Maheshri N. 2010. Noise can induce bimodality in positive transcriptional feedback loops without bistability. Science 327: 1142-1145.

Weinberger LS, Shenk T. 2007. An HIV feedback resistor: Autoregulatory circuit deactivator and noise buffer. PLOS Biol 5: e9. doi: 10.1371/journal.pbio.0050009.

Zhang X, Rosenstein BS, Wang Y, Lebwohl M, Wei H. 1997. Identification of possible reactive oxygen species involved in ultraviolet radiation-induced oxidative DNA damage. Free Radic Biol Med 23: 980-985. 


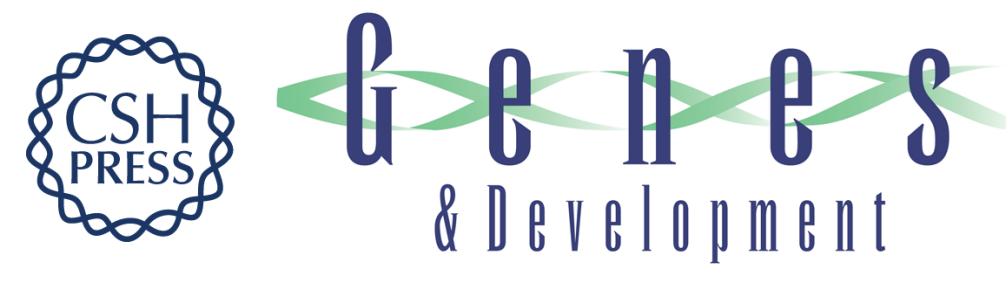

\section{Synthetic memory circuits for tracking human cell fate}

Devin R. Burrill, Mara C. Inniss, Patrick M. Boyle, et al.

Genes Dev. 2012, 26:

Access the most recent version at doi:10.1101/gad.189035.112

Supplemental
Material http://genesdev.cshlp.org/content/suppl/2012/07/02/26.13.1486.DC1

References This article cites 34 articles, 13 of which can be accessed free at: http://genesdev.cshlp.org/content/26/13/1486.full.html\#ref-list-1

License

Email Alerting Receive free email alerts when new articles cite this article - sign up in the box at the top Service right corner of the article or click here.

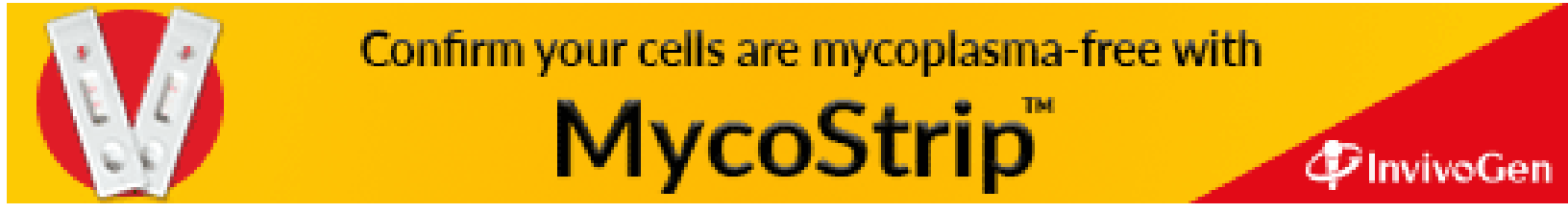

